\title{
ADEQUAÇÃO DO INDICADOR DE INTERVENÇÃO FARMACÊUTICA
}

LÍVIA MARIA GONÇALVES BARBOSA', DEBORA CECILIA MANTOVANI FAUSTINO DE

CARVALHO'2.

HOSPITAL SÍRIO-LIBANÊS

${ }^{1}$ Coordenadora de Farmácia, Hospital Sírio-Libanês, SP

${ }^{2}$ Gerente de Farmácia, Hospital Sírio-Libanês, SP

\section{INTRODUÇÃO}

A farmácia clínica é um serviço que se estabeleceu no Brasil, no contexto hospitalar, através das exigências das certificadoras de qualidade.

Ainda existe falta de homogeneidade quanto a apresentação dos dados dificultando a comparação entre serviços.

\section{OBJETIVO}

Descrever a adequação do indicador de farmácia clínica em um hospital de grande porte.

\section{MÉTODO}

Foram utilizados dados de janeiro de 2017 a outubro de 2018, coletados através de ferramenta institucional. Até 2017, o indicador era obtido através da formula: $\mathbf{N}$ de intervenções realizadas dentro do sistema $+\mathbf{N}$ de intervenções realizadas fora do sistema/N de itens analisados no sistema de gestão da farmácia clínica. Entendendo-se que o processo de cuidado envolve mais que a análise da prescrição do paciente foi sugerido em 2018 uma adequação.

O número de oportunidades encontradas na avaliação do paciente não necessariamente estaria relacionadas aos itens analisados, o denominador passou a considerar o número de pacientes/dia/mês, considerando que todos os dias o farmacêutico poderia identificar novas oportunidades de intervenção para a melhoria do tratamento durante a internação do paciente. Desta forma, foram estabelecidos dois indicadores distintos: intervenção farmacêutica relacionada a processo para mostrar a qualidade da prescrição e intervenção farmacêutica relacionada a clínica que mostra o aumento da segurança do paciente na utilização de medicamentos e outros produtos para a saúde.

\section{RESULTADO}

Gráfico 1: Resultado de 2018.

Densidade de intervenção farmacêutica/paciente-dia/mês 2018

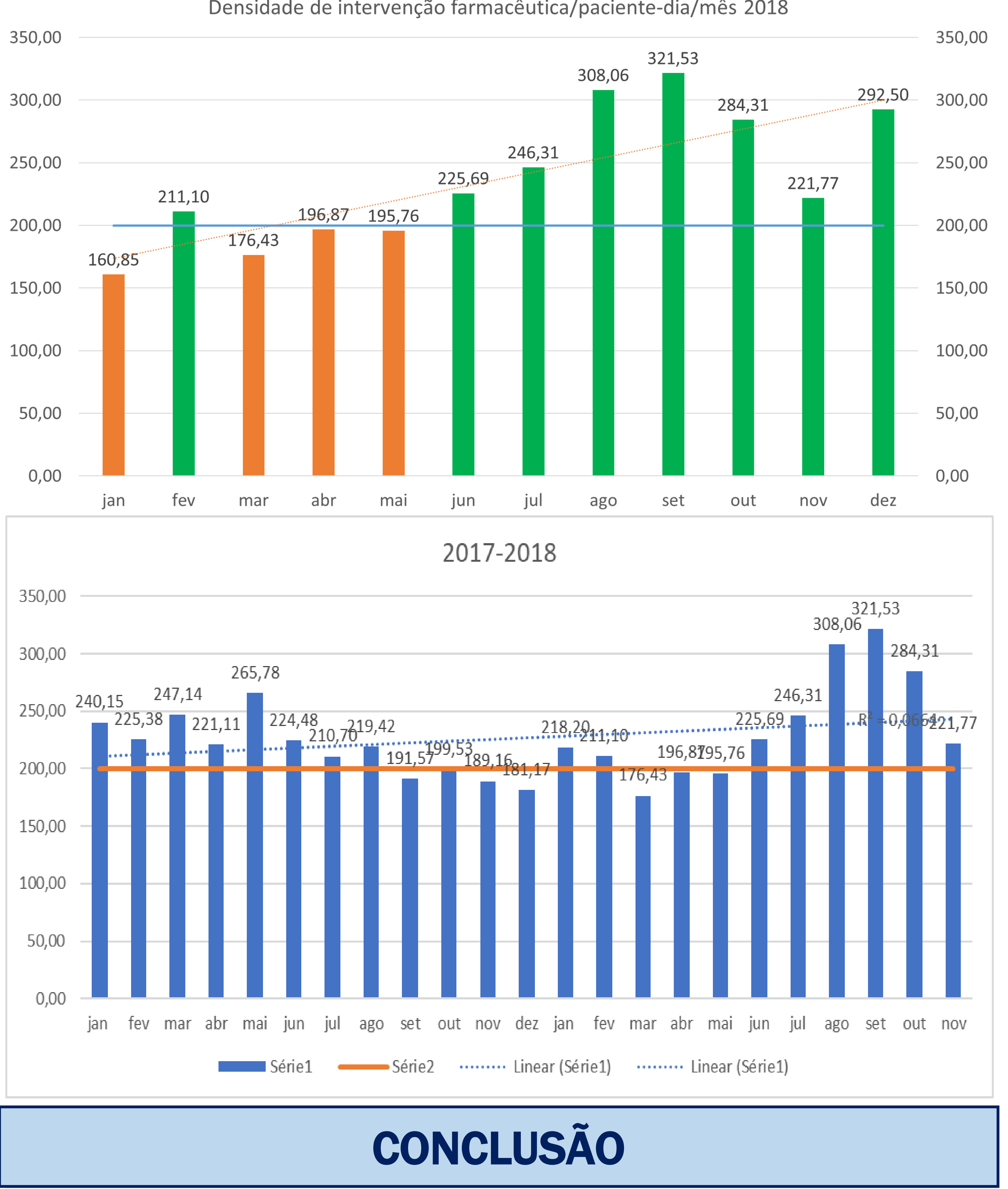

A análise crítica dos indicadores é fundamental para que o serviço possa mostrar de forma eficiente para os gestores e para a equipe como o processo é realizado. A adequação do indicador de intervenção farmacêutica possibilitou a apresentação mais clara da atuação do farmacêutico clínico. As perspectivas futuras apontam para a necessidade de relacionar intervenções com desfechos do paciente.

\section{REFERÊNCIAS BIBLIOGRÁFICAS}

1. Kjeldsen L.J., Olesen C., Hansen, M.K., Nielsen, TRH. Clinical Outcomes Used in Clinical Pharmacy Intervention Studies in Secondary Care. Pharmacy, 5, 28. 2017.

2. Chamoun, N.R., Zeenny R., Mansour, H. Impact of clinical pharmacy interventions on medication error nodes. Int J Clin Pharm. 2016. 